RESEARCH ARTICLE

\title{
Occupational Therapy in Oman: The Impact of Cultural Dissonance
}

\author{
Najat Saif Mohammed Al Busaidy ${ }^{1}$ \& Alan Borthwick ${ }^{2 * \dagger}$ \\ ${ }^{1}$ Armed Forces Hospital, Occupational Therapy Department, Seeb, Oman \\ ${ }^{2}$ Faculty of Health Sciences, University of Southampton, Southampton, Hampshire, United Kingdom
}

\begin{abstract}
Occupational therapy theory and philosophy are broadly considered to be based on Western cultural values. In contrast, the application of theory and practice in the Sultanate of Oman, historically based on traditional Middle Eastern and Islamic cultural values, provides a case exemplar, which highlights both paradigmatic differences and cultural dissonance. Drawing on the experiences of occupational therapists working in Oman, this study found that the application of therapeutic goals aimed at patient independence and autonomy were difficult to achieve in an environment where family duty and responsibility for care were highly prized. Dressing and cooking assessments were challenging, and issues related to gender proved problematic. Therapists found the need to adapt practice to acknowledge these differences, and to adopt pragmatic problem-solving strategies, without resolving the underpinning philosophical contradictions. Occupational therapy in Oman is under-researched; further work is needed to confirm the cross-cultural validity of specific assessments and practice models. Copyright @ 2012 John Wiley \& Sons, Ltd.
\end{abstract}

Received 5 December 2011; Revised 3 May 2012; Accepted 4 May 2012

\section{Keywords}

cultural dissonance; Oman; occupational therapy theory

*Correspondence to:

Alan Borthwick, Faculty of Health Sciences, University of Southampton, Southampton, Hampshire, United Kingdom.

†Email: ab12@soton.ac.uk

Published online in Wiley Online Library (wileyonlinelibrary.com) DOI: 10.1002/oti.1332

\section{Introduction}

Most studies of healthcare practice focus on, or are derived from, professional activities within Western liberal democracies (Hopton and Stoneley, 2006). Relatively little attention is paid to the nuances, subtleties and influences of non-Western cultures and their impact on professional practice (Awaad, 2003a), particularly in Arab cultures (Jabbour, 2003). In this study, the importance of cultural beliefs and values to the practice of occupational therapy in Omani society is explored. Occupational therapy is largely constructed and understood within Western, Anglo-American culture, where role and task domains relate to, and conform to, Western cultural norms (Yamey and Greenwood, 2004; Taylor and Hudson, 2005; Nelson, 2007; Cole and Tufano, 2008). As a profession essentially created within, and for, Western societies, the delivery of occupational therapy in nations with very different cultural norms and social "values", such as in Arabic nations, merits attention (Diasio-Serrett, 1985; Canadian Association of Occupational Therapists, 2010; Carswell, 2011; Brintnell, 2012). Liberal democracies, most evident in Western Europe and North America, tend to privilege the individual over society (Nettleton, 1997). Individual freedom and personal autonomy are noted as values central to these liberal political ideologies, and are often used to 
characterize "Western" values, in contrast to non-Western nations, such as socialist China, or Middle Eastern monarchies or republics, which place greater stress on the collective identity of family (Saks, 1995; Nettleton, 1997; Malin et al., 2002; Eccleshall, 2003). Indeed, Arab societies have been referred to as "collective" rather than "democratic and individualistic" in orientation (Dwairy and Van Sickle, 1996).

\section{Occupational therapy and cultural dissonance in Oman: ideological and theoretical considerations}

Most accounts view occupational therapy practice and theory as embedded in Western cultural values, with clear implications for service provision and design in the non-Western world (Awaad, 2003a; Byford and Veenstra, 2004; Taylor and Hudson, 2005; Hopton and Stoneley, 2006). Awaad (2003a) asserted that the imposition of Western concepts of occupational therapy practice on cultures with "very different" beliefs, values and attitudes may constitute a "potential hazard", and run the risk of being "inappropriate" or irrelevant to local situations, and may give rise to conceptual and philosophical conflicts (Byford and Veenstra, 2004; Hopton and Stoneley, 2006). Central to the debate is the emphasis in Western care models on enhancing individual independence, in contrast to Eastern and Arab/Islamic paradigmatic beliefs centred on fatalism and family responsibilities (Awaad, 2003b; Yamey and Greenwood, 2004; Taylor and Hudson, 2005).

At a deeper level, this may be seen as a fundamental clash of ideological values, contrasting embedded neoliberal values, which stress the importance and desirability of individual freedom and responsibility, with communitarian values, stressing responsibility towards family and social groups (Malin et al., 2002). Within occupational therapy, these values are translated into notions of personal autonomy, the enabling and empowerment of individuals through client-centred goal directed therapy, which maximizes health and function (Awaad, 2003a). In contrast, in Arab cultures, family roles may be placed above the needs of individuals, where "honouring the family, acquiescence. . and passivity may be regarded as healthy adaptations to life changes" (Dwairy and Van Sickle, 1996; Awaad, 2003a). Occupational therapy constitutes a particularly relevant case exemplar, as cultural competency is viewed as a core prerequisite for effective practice (Reed and Sanderson, 1999; Chiang and Carlson, 2003; Yamey and Greenwood, 2004; Taylor and Hudson, 2005; Iwama, 2007; Nelson, 2007; Lim, 2008).

The significance of culture in occupational therapy practice has been acknowledged in the literature (Fitzgerald, 2004; Nelson, 2007). Culture is viewed as the learned behaviours, values, norms and principles that are passed on from one generation to another in a given population (Loveland, 1999; Chiang and Carlson, 2003). Culture has also been defined as a "dynamic and ever evolving concept" that is continuously changing from one group to another and from time to time (Chiang and Carlson, 2003; Yau, 2003) and as an accumulated resource that defines behaviours, which is learned by an individual within a particular social group (Awaad, 2003a). Al-Abdulwahab and Al-Gain (2003) argued that attitudes towards issues such as disability, for example, embrace cultural values, educational backgrounds and religious beliefs. Cultural differences in health beliefs and values, asserted Hume (2002), may lead to misunderstanding or even misdiagnosis. It has been claimed that the profession of occupational therapy was founded by George Barton, in 1914, following a personal battle with disability (Cole and Tufano, 2008). In light of the historical evolution of the occupational therapy profession, the American Occupational Therapy Association defined occupational therapy as "the art and science of directing man's participation in selected tasks to restore, reinforce and enhance performance, facilitate learning of the skills and functions essential for adaptation and productivity, diminish or correct pathology and to promote and maintain health" (Reed and Sanderson, 1999, p. 5).

The use of "occupation" is viewed as the main focus in intervention, which links the profession to its roots, yet it remains an umbrella term to describe all phases of occupational therapy practice (Lamport et al., 2001). Indeed, "occupation" constitutes one of the "tools" of occupational therapy therapeutic intervention (Reed and Sanderson, 1999). Clients engage in occupations that are highly influenced by culture (Kielhofner, 2002). Everyday occupations comprise features that reflect patterns of belief and related behaviours (Hasselkus, 2002). The global growth of the occupational therapy profession, with a diverse client population (Kirsh et al., 2006) means that occupational therapy activities and modalities of practice may need to be tailored to suit specific groups or individual's needs (Awaad, 2003a; Cusick, 2006). Many of the literature, to date, on the 
impact of culture on practice in occupational therapy lacks an empirical basis and is often considered purely descriptive in nature (Kelly, 1995; Awaad, 2003a).

\section{Occupational therapy and cultural dissonance in Oman: practical considerations}

Occupational therapy in Oman was first established as part of the Armed Forces Medical Services in 1985, staffed with non-Omani occupational therapists(OTs) until 1998, when the first Omani therapist qualified in England (Greene, 2009). The Ministry of Health $(\mathrm{MOH})$, the Royal Oman Police and the Royal Army of Oman are the main providers of health care. Currently, the population of OTs has reached 15. OTs in Oman work within the MOH, the Armed Forces Medical Services and the Ministry of Social Affairs. Exporting occupational therapy to non-Western nations (and cultures) such as Oman has led to a variety of culturally related conundrums for its practitioners (Cusick, 2006; Kirsh et al., 2006; Malinak, 2007). Culture impacts on aspects of daily life, such as behaviour, thoughts, judgements and broad views of the world, and is therefore reflected in the activities of daily living (Chiang and Carlson, 2003; Hopton and Stoneley, 2006). Establishing useful, fruitful and productive relationships with clients is, in part, dependent upon cultural competence (Hsiao et al., 2006; Carmody et al., 2007; Iwama, 2007). Each has implications for practice, for example, in areas such as assessments, the acceptability of gender roles, beliefs about recovery in rehabilitation, or the influence of traditional medicine or beliefs relating to coping with disability. In the latter example, disability has been variously considered the result of personal deeds, the malevolence of evil spirits or a breach of tribal taboo (Byford and Veenstra, 2004; Yamey and Greenwood, 2004). In traditional Omani society, ill health is linked to the presence of "Jinn", a version of evil spirit possession (Al-Adawi et al., 1997). Similar cultural beliefs are said to be common across the Arab Islamic world (Al-Adawi et al., 2002; Dwairy, 1998; Ghuloum and Ibrahim, 2006).

In the Middle East, traditional beliefs in the supernatural may be intermingled with profound Islamic religious beliefs, as a form of fatalism attributing life events solely to the "will of Allah" (Borkan et al., 2000; Razali et al., 2002). Rehabilitation models assume that patients will seek recovery and are able to actively influence it (Yamey and Greenwood, 2004). Within Islam, however, recovery is often viewed as exclusively a matter for God to determine and may encourage passivity (Yamey and Greenwood, 2004; Al-Krenawi, 2005; Ypinazar and Margolis, 2006).

Family structure is considered more cohesive in Islamic Arab societies, as in Oman, than in the Western world (Hammad et al., 1999). In Omani Society, family and tribal structures are viewed as extremely influential in shaping personal values and behaviours (Malinak, 2007). It is the norm in Islamic cultures for the immediate family to take central responsibility for an ill family member, as a social obligation and duty (Fitzgerald et al., 2001; Chen et al., 2004; Fitzgerald, 2004; Yang et al., 2006), offering both physical and psychosocial support (Dhami and Sheikh, 2000).

\section{Methods}

A qualitative research methodology was adopted to provide an account that would yield rich, insightful and informed data addressing the study aims. The data in this study were derived from a series of 10 semi-structured interviews, obtained via a criterion-based sampling strategy. Oman is a country with a small population of OTs; there are only 15 qualified therapists working in Oman in total. The initial intention was to recruit the entire population of OTs in Oman to the study. As the participants were identified through key individuals from the $\mathrm{MOH}$, Ministry of Defense and the Sultan Qaboos University Hospital, recruitment of participants was on a voluntary basis, achieved through approaching the general managers of all the three hospitals that provide occupational therapy services in Oman. Those with less than 6 months experience of working in Oman were excluded from the study, on the grounds that they would be less able to contribute insights into the issues being explored. In total, 11 OTs were recruited. This represented $75 \%$ of the whole OT population of Oman.

Data were analysed using a constant comparative. The data are presented as a thematic narrative, deploying extracts from interview transcripts to illustrate key points. Interviewees are not identified for ethical reasons, but featured extracts are designated codes.

Ethical approval was obtained jointly between the authorized body within the three Omani hospitals in which the study took place and via the University of Southampton, Faculty of Health Sciences Ethics Committee. Data were captured using an Olympus (Olympus 
UK Ltd, 2-8 Honduras Street, London EC1 OTX, UK) DS-30 Digital Voice recorder. Data was downloaded onto an HP laptop computer using the Olympus DSS Player package (DS-2300). Data was then transcribed using the Olympus AS-2300 PC transcriber unit.

\section{Findings}

Analysis revealed three central themes, which relate to the issues of culture/religion, gender and beliefs in witchcraft and traditional medicine.

It was clear from the data that professional values based on Western notions of rehabilitation did give rise to problems, identified as cultural in origin, presenting practitioners with the need to adapt practices to "fit" the demands of a distinctly different environment.

...most of the interventions we learn is all to do with the Western lifestyle. Although ... trying to be very culturally sensitive, but still probably, when they face reality, it is a totally different story. I mean, even for us Omanis coming back [following training abroad] it was a challenge to adapt ourselves, to train ourselves, of how to tackle the cultural influences within our practice. . . because, as I said, working in the West, coming back here, we have to change our whole perception about what we studied as occupational therapists. We have to be very problem based. We have to find solutions for problems that people never think about in the West. (Interviewee 7)

One key feature evident throughout was the finding that the precept of independent living, so central to the ethos and philosophy of occupational therapy, was difficult to enact in a culture where this value was not shared and not, therefore, encouraged.

Many parts of the assessments we generally don't do here, or, rather, I've not done a proper dressing or a grooming or kitchen assessment. I haven't done any of these because if you see each house, each family, "Omani family", they will have a housemaid or a lot of people to assist them. (Interviewee 2)

Self-care assessments were also affected by cultural norms. For example, washing and dressing assessments were never applied, especially to clients of the opposite sex. Indeed, these reflected important religious taboos, which rendered their exercise impossible as many were considered to be contrary to Islamic teaching.

So things like washing and dressing, which is a very common practice for occupational therapists in the UK, is something that we never, I would say, do here. It's not acceptable at all, to expose your body to a foreigner, I would say, unless it was an emergency for example, when nurses wash them. But the majority won't accept the idea that you stand [and] observe them while they are doing their washing or dressing. (Interviewee 7)

Within Omani culture, the dressing code is derived from the requirements of the Islamic religion, where women must wear head scarves and long dresses. Dressing assessments and practice are thus complicated by the extra demands involved for practitioners.

I would say our dressing code ... particularly of ladies, we wear head scarves or a veil, so you've got many patients who come, for example, who are 'Hemis' [hemiplegia] or again lessened in the ability to use an arm, [following an] amputation or anything. If you think about wearing a veil with one hand it can be very, very challenging, so you have to teach them other methods of, for example, doing that. (Interviewee 7)

Nor is this problem gender specific. Traditional Omani dressing code for men may also pose challenges. One of the respondents referred to the button of the men's everyday clothing item, known as "Dishdasha", where the button is very small in size and mostly difficult to manipulate using one hand.

Dressing assessment in Oman for example, if you take the stroke patients or head injury cases, they feel difficult [using only] one hand ... because they are wearing 'Dishdasha' ... .we can manipulate with the other hand but there are some activities which ... for them it is very difficult, because the buttoning is very small ...with one hand holding the two things it is ... difficult for the patient. (Interviewee 2)

Similarly, when conducting cooking assessments, respondents reported that most Omani homes had domestic workers or cooks provided for the family; cooking was not, therefore, considered a priority in establishing independence - a recurring theme. 
So if it is a head injury, or a CVA lady [sic] who comes to me, by the end of her rehabilitation program a kitchen assessment or a self help skills assessment in dressing will be inappropriate because she wouldn't do anything back home. She has someone to help her all the time and most of them are ladies who don't cook for themselves or their families; only at home, because they have a chef or a housemaid or someone who can do things for them at home - that is purely cultural in Oman. (Interviewee 2)

As most of the occupational therapy available in Oman is provided in urban areas near the capital city, with little delivered in rural areas, it is likely that personal wealth would play a role in determining the presence of housemaids and other paid employees (Al Balushi and West, 2006; Al-Kharusi, 2008; Greene, 2009). However, in poorer homes or in rural areas, the burden is transferred to other family members. Indeed, in rural areas, there as often further subtle differences, demanding adaptations to practice.

For example, most of the families in the rural areas use low furniture, requiring the therapists to switch their assessments and treatment modalities to suit their client's needs.

But [in rural areas] most of the time people, you know, have provisions to sit on the floor, like their carpeted floors and ... good cushioned floor arrangements for sitting. So in such a house, if you tell them you have to do chair sitting, or you have to sleep on the bed, ... its very different for them, so there is so much to learn in the process for them, it's like changing lifestyle totally. (Interviewee 8)

[For an] occupational therapist this is even more challenging, how do they help the client, for example, transfer from a wheelchair to a mattress on the floor? (Interviewee 7)

\section{Witchcraft and traditional medicine in Oman}

Unlike Western cultures, in which disability and illness are largely understood within the medical model, in Omani cultures, there remains persistent residual belief systems of religious relevance, either evident as the
"Will of Allah" or, in some instances, witchcraft (Miles, 1995; Ypinazar and Margolis, 2006; Malinak, 2007). Several of the respondents underlined instances in which clients were reluctant to accept Western beliefs around the value of occupational therapy, preferring to attribute disability to evil spirits or witchcraft, thus necessitating some remedial action involving the purging of evil spirits. In one instance, for example, an Omani respondent found that several patients suffering from mental health problems, in which hallucinations featured as symptoms, were attributed to "Jinn", ${ }^{1}$ as a manifestation of the work of evil spirits.

...we know that 'Jinn' exists [for many people], our religion says that, our culture says that. But we notice that some occupational therapists, they will think immediately, that is delusional, or this is one of the hallucinations, so they can't relate it to the culture the patient came from. (Interviewee 4)

I've experienced it a lot. .. there were a lot of small children with cerebral palsy who had burning scars on their chests. And they also had amulets ${ }^{2}$ which would protect them against evil spirits.... (Interviewee 1)

The degree to which these beliefs were both culturally Omani, and embedded in society, was, to some extent, reflected in the views expressed by the Omani OTs, who acknowledged a lingering echo of belief in the concept of evil spirits themselves.

And to be honest, even us as therapists, we sometimes, I personally sometimes do believe in that. Sometimes it's just, for example, your fate, or what 'Allah' has written for you, but you know in the country here, we would say in this area there are a lot of Demons, there is a lot of black magic going on, and anything can happen to you. And strongly inside, even if you say no, they are not there, but strongly inside each one of us probably, [we] do believe in it in some way. (Interviewee 7)

\footnotetext{
1 "Jinn" is a term for "evil spirits" within Islam, mentioned in the Quran. ${ }^{2}$ In this instance, the interviewee was referring to a pendant, which parents would place on their child for protection. Some contain inscriptions from the Quran.
} 
Alongside beliefs in witchcraft, the majority of respondents came across cases where clients left therapy programmes to attend "traditional medicine" consultations. One treatment referred to by a participant was to burn the patients with a hot iron rod, a practice clearly incompatible with the treatment philosophy of Western occupational therapy.

The main thing I've noticed here, is applying a hot iron rod to the disabled child, which will affect the [OT] treatment, like, for example, they are coming here for treatment one month, or two months, then once again they are going back to that kind of 'cultural' treatment modality. Then the children have to [have] bed rest to heal that. So once they come back they are going back somehow behind the stage.... (Interviewee 2)

I mean its things that they have inherited from long, long generations ago, and they are still using it. Things like 'Al Wasm'... It's when they burn the client or put them in the hot rooms and stuff. ${ }^{3}$ (Interviewee 7)

Alternative, traditional medical practices such as "Al Wasm" clearly conflicted with, and often interrupted progress in, mainstream occupational therapy initiatives. It was not, then, possible for the therapists to accept the former as complementary to the latter, as is more common within the range of "CAM" therapies, such as acupuncture, recognized in the West (Saks, 1995).

For example, here I have treated one child, CP diplegic. He came regularly for treatment. He is a very good candidate and I suggested him for surgery and vigorous treatment here, then they went for the culturally traditional methods, and the child has to rest for a couple of months to heal that. So it effects the treatment for me and the children. (Interviewee 2)

Several other traditional interventions were reported by the respondents, largely involving practices that would not qualify as complementary to Western therapeutic

3"Al Wasm", is "curing by fire", and involves applying a hot iron rod to the part of the body affected by disease or injury. Hurreiz SHA (2002), Folklore and Folklife in the United Arab Emirates, London: Routledge Curzon. regimes. Yet, at the same time, the therapists themselves on occasion seemed to grant a hesitant and tentative degree of legitimacy to some of these practices, perhaps implying the extent to which these methods were culturally embedded.

...the mother was swearing, she was like 'Wallahi', 4 this happened to my daughter. She had an autistic child, which couldn't walk I think to the age of two or something. She said, 'I heard it from a very old grandmother', and she said, 'I'll try it, it will not cause any harm to my daughter'. You know the ants, big ants, the black ants, the big ones. She says, you hit them so that they are between being alive and dead. Ok, you take that ant, and you rub it on the sole of the child's feet. She said, 'the first day my child was able to stand, second day I did the same thing and she was able to take a few steps', and the third day she was swearing she was able to walk independently. And we see the child here, and she is [now] perfectly fine I would say. (Interviewee 7)

\section{Gender, Islam and occupational therapy in Oman}

Perhaps predictably, one of the key obstacles to practice arose with the issue of gender, amplified in situations where, because of very low staffing levels and high demand, male OTs were obliged to cover for female colleagues. Simple issues, such as cover for annual leave, would have unintended consequences for therapy outcomes. Difficulties were reported in establishing interpersonal relationships between clients and therapists and, on many occasions, hindered the progress of therapy programmes.

Yes, at times, like when I, as you know in this department, it's just me and one other, male, therapist, and when I go on vacations I have to either cancel all my patients, or they do home programmes, or something, until I come back, because many of them don't wish to be seen by the male occupational therapist, so they miss out on a lot of sessions, and so the end results become a little slower. ... (Interviewee 3)

\footnotetext{
" "Wallahi" is to "swear by the name of Allah", to emphasize the veracity of the statement being made or to persuade the listener.
} 
Again, the therapists themselves were, on occasion, also influenced by their own cultural norms, as is evident in the following extract, in which one of the Omani respondents expressed a degree of personal discomfort paralleling that of her patients.

We prefer females seeing females, and males seeing males, to avoid any, you know, other problems that can happen. Especially, when you are a young therapist, and you've got a young man coming in, and here in this culture, being touched by a female is a very, oh, very big thing. So sometimes we prefer, if we see that we are not comfortable, us therapists as well, we would give it to the same gender [sic]. (Interviewee 7)

In most instances, the issue of gender was inextricably linked to Islamic religious belief and customs, clearly deeply embedded in Omani society. Seven of the participants acknowledged that their therapy practice was influenced by Islamic religious belief and customs. It was considered to permeate every facet of life and could be both harnessed to therapeutic advantage and yet present therapy with considerable difficulties. By using examples from practice, the respondents illustrated the variety of impact powerful religiosity had on everyday therapy.

The positive side is that, people have confidence, in that someone else, God, will help them achieve things, so then it can increase their motivation and activities. But it depends on how people work on it, and if they keep the responsibility also within themselves, or if they put the responsibility completely on a bigger power. (Interviewee 1)

Islam does, any religion influences culture, the way people behave, the way people talk, interact, and establish relationships in society. So Islam influences culture. I should say, it influences more than any other religion, ah, because, especially Omanis with whom I'm dealing with, they are very fond of their religion. So the entire way of life depends on the religion, the religious practices, the religious ways of relationships, communication, the customs, the traditions you know, all these things are influenced by religion. (Interviewee 5)

One key exemplar with huge significance for the exercise of occupational therapy as both a principle and parents or relatives, or those who are disabled or unwell, involves adopting roles, which ensure dependency and obscure the likelihood of independence following rehabilitation. Such a fundamental tenet of Western occupational therapy had to be recast by the therapists in Oman to a version of care, which permitted dependence, yet continued to offer aspirations to independent living.

... as our role as occupational therapists, our role is to make the person to be independent in their life [sic]. But in Islam also, we have to take care of anybody [that] is not able to do their own, or they are not able to take care of themselves, ah, so sometimes this also can affect our practice. (Interviewee 4)

Yet, although the beliefs generated through the Islamic faith encouraged acceptance of disability and a fatalistic view that each was the result of the will of "Allah", there was also a belief that their prayers for better health might be answered, enabling a more positive approach to therapy.

Another positive thing is the religious beliefs like, so they, 'in the name of Allah' they say, everything is done, and they have a strong belief that God will definitely answer their prayers, and then it'll be done. (Interviewee 10)

In addition, the role of the family, as carers, could be channelled to support therapeutic interventions, ensuring better outcomes whilst engaging family caring. In that way, even when therapy input ceased, there was a certain expectation that therapy would continue in the hands of the family carers.

...I feel the best part of this culture is, the family support, and the strength, if you convince the family you think your work is done, the patient will do it. So that is the thing I feel is influencing my professionalism a lot. (Interviewee 8)

Where this became problematic, of course, was when the transition to independence was delayed or even prevented by ongoing family care.

Ah, sometimes patients, they say 'what do you mean that my family will not take care of me? What do you think, I'll be all alone? Why should I do this?' And even the family gets offended 
sometimes; 'you think we'll not do this for him? We will do everything, I mean he does not have to actually move around by himself, we'll propel the wheelchair for him, you don't have to give him an electric wheelchair or something.' So, this is the negative aspect, which sometimes hinders the patient [from becoming] independent. (Interviewee 8)

\section{Discussion}

The practice of occupational therapy in Oman provides a rich case study exemplar of cultural dissonance and the strategies employed to adapt to such circumstances. In broad terms, the disjunction between the philosophical principles underpinning Western occupational therapy practice and those of an Islamic culture centred on family responsibilities and support, coupled with a fatalistic view of life events, appears at face value to militate against effective therapeutic care. Furthermore, when overlaid by a pre-existing and prevalent tradition of mysticism, adherence to Western principles may seem unsustainable in practice. Clearly, three intermingled cultural themes impacted on practice: religious beliefs, gender issues and traditional beliefs and practices, such as witchcraft. Islam provided guiding principles, which were central to Omani lifestyle and thought. While tending to encourage passivity at one level, in ascribing health outcomes to God irrespective of therapeutic input, it also served in some instances to assist in giving confidence to patients that their efforts to regain or improve health would have God's help. Encouraging prayer was perceived to assist in bringing a more optimistic attitude to therapy. Similarly, to adapt to the tendency towards passivity, the OTs encouraged family involvement in therapy so that it would continue even after the formal therapy sessions were completed.

Gender issues also presented obstacles, particularly where dressing assessments or consultations with the opposite sex were concerned. Again, the therapists adapted to these constraints by, for example, advising on home programmes of care rather than arranging consultations with therapists of the opposite sex, thus avoiding breaching social and religious taboos.

Reliance on traditional forms of medicine also proved a challenging issue, particularly where actual harm to the patient might ensue (for example, the practice of "Al Wasm"). Whereas these treatments could not be endorsed, others were easier to accept and legitimize as complementary, such as the practice of rubbing dead ants onto the soles of the feet or the use of amulets with inscriptions from the Quran. Demonstrating an acceptance of beliefs in "Jinn", which were already familiar to the Omani therapists, enabled easier relationships with clients and promoted therapeutic engagement.

For the OTs, adapting to cultural dissonance centred on adopting pragmatic, problem-based solutions, abandoning cooking assessments when these were evidently less relevant, while focusing on other problems, such as dressing assessments, where Islamic dress (head scarfs or "Dishdasha") required greater detailed input from the therapists. Assessments were adapted to suit individual needs, and required culturally sensitive negotiation, as, for example, where only low furniture was available, with mattresses on the floor instead of Western-style beds.

Shedding light on the applicability, compatibility and utility of Western principles underpinning occupational therapy for a cultural and geographical region under-represented in the literature has yielded insights into the difficulties presented by a complex social, cultural and religious mix. In attempting to establish the legitimacy of the methods and principles of occupational therapy in a cultural milieu in which socially powerful alternative and competing values exist, the therapists faced considerable challenges. Yet, it is also clear that, in some instances, harnessing the authority of established values could be utilized to produce outcomes compatible with some principles of Western therapeutic care. The evidence presented here does give some indication of the strategies adopted and the progress made by individual OTs in adapting to these challenging circumstances (see also Kirsh et al., 2006). Pragmatic solutions to practical problems are both possible and evident. Less clear is the way in which the underpinning principles might be fully realized in practice. Imposing values centred on individualism and independence in a context that conflicts with both religious and cultural dimensions posed problems for the therapists, who, through pragmatic approaches, largely avoided confronting the philosophical dilemma. Nevertheless, these adaptations were important concessions.

Working in parallel with other practices underpinned by belief systems stressing supernatural explanations for illness, accompanied by traditional treatment regimes, some of which were injurious to the clients, was also deeply problematic. 
Nevertheless, the respondents did consider that clients' devotion to Islam gave emotional strength in facing the challenges of illness and disability (as in Borkan et al., 2000; Ismail et al., 2005).

Care for sick relatives was viewed as a central part of Islamic teaching, a duty of care grounded in a family oriented, communitarian context. Yet, this, too, was drawn upon to harness the engagement of family in ongoing therapy.

Overall, this study uncovers and illuminates a growing concern confronting occupational therapy as a profession, one not exclusive to Oman, but evident wherever the current ideological and philosophical stance of occupational therapy is transported across cultural boundaries of meaning, into diverse contexts of practice. As Iwama (2003) asserted, to "coerce" others to comply with Western, mainstream perspectives would "forfeit the requirement of meaning in occupation and occupational therapy" and that one way forward would be to "encourage other cultural groups to reinvent occupational therapy along culturally meaningful and relevant lines". Perhaps, the findings in this study point to ways in which this may be evolving, as new, pragmatic, approaches to practice are gradually defined. In doing so, however, the tendency to simply circumvent problematic philosophical and cultural contrasts, while possible to an extent, is not ideal. Embedding practice that is underpinned by cultural and religious meanings relevant to Omani clients is essential, and the therapists in this study, in justifying the practical adaptations adopted, hint at the possibilities of "reinventing" an occupational therapy compatible with Omani culture and society. Equally, it is clear that there is a pressing need for support for OTs faced with the task of translating Western philosophical and cultural ideals, embedded in contemporary, mainstream occupational therapy knowledge, theory and practice, into their clients' cultural contexts of daily living. Perhaps, the profession itself, via its research academics and theorists, may also have cause to reconsider its approaches to philosophical and research questions, in the development of new, culturally sensitive models, instruments and knowledge.

\section{REFERENCES}

AL-Abdulwahab SS, Al-Gain S (2003). Attitudes of Saudi Arabian health care professional towards people with physical disabilities. Asia Pacific Disability Rehabilitation Journal 14(1): 64-70.

Al-Adawi S, Burjoree R, Al-Issa A (1997). Mu-Ghayab: a culture-specific response to bereavement in Oman. The International Journal of Social Psychiatry 43(2): 144-151. Al-Adawi S, Dorvlo ASS, Al-Ismaily SS, Al-Ghafry DA, Al-Noobi BZ, Al-Salmi A, Burke BT, Shah MK, Ghassany H, Chand SP (2002). Perception of and attitude towards mental illness in Oman. The International Journal of Social Psychiatry 48(4): 305-317.

Al Balushi MQ, West DJ (2006). A model for hospital reforms in committee structure \& process improvement in Oman. Journal of Health Sciences Management and Public Health 7(1): 30-41.

Al-Kharusi W (2008). Update on road traffic crashes, progress in the Middle East. Clinical Orthopaedics and Related Research 466(10): 2457-2464.

Al-Krenawi A (2005). Socio-political aspects of mental health practice with Arabs in the Israeli context. Israel Journal of Psychiatry \& Related Sciences 42(2): 126-136.

Awaad T (2003a). Culture, cultural competency and occupational therapy: a review of the literature. British Journal of Occupational Therapy 66: 356-362.

Awaad T (2003b). Culture, cultural competency and psychosocial occupational therapy: a Middle Eastern perspective. British Journal of Occupational Therapy 66(9): 409-413.

Borkan JM, Aorad M, Shvarts S (2000). Universal health care? The views of Negev Bedouin Arabs on health services. Health Policy and Planning 15(2): 207-216.

Brintnell ES (2012). President's message, World Federation of Occupational Therapists. (Available at: http://www. wfot.org/AboutUse/PresidentsMessage.aspx) (Accessed 14 February 2012).

Byford J, Veenstra N (2004). The importance of cultural factors in the planning of rehabilitation services in a remote area of Papua New Guinea. Disability and Rehabilitation 26(3): 166-175.

Canadian Association of Occupational Therapists (2010). World Federation of Occupational Therapists: history. (Available at: http://www.otlegacy.ca/past/WFOT.htm) (Accessed 14 February 2012).

Carmody S, Nolan R, Chonchuir NN, Curry M, Halligan C, Robinson K (2007). The guiding nature of the kawa (river) model in Ireland: creating both opportunities and challenges for occupational therapists. Occupational Therapy International 14(4): 221-236.

Carswell A (2011). The World Federation of Occupational Therapists and the Canadian Association of Occupational Therapists: a collaborative venture. Occupational Therapy Now 13(1): 22-24.

Chen RK, Jo S, Donnell CM (2004). Enhancing the rehabilitation counselling process: understanding the obstacles 
to Asian Americans' utilization of services. Journal of Applied Rehabilitation Counselling 35(1): 29-35.

Chiang M, Carlson G (2003). Occupational therapy in multicultural context: issues and strategies. British Journal of Occupational Therapy 66: 559-567.

Cole MB, Tufano R (2008). Applied Theories in Occupational Therapy: A Practical Approach (1st Edition, pp. 3-21). New Jersey Thorofare: Slack Incorporated.

Cusick A (2006). Occupational therapy in action: local and global. Guest Editorial. OTJR: Occupation, Participation and Health 26(2): 43-44.

Dhami S, Sheikh A (2000). The Muslim family: predicament and promise. Western Journal of Medicine 173: 1-5.

Diasio-Serrett K (1985). Another look at occupational therapy's history: paradigm or pair of hands? In: DiasioSerrett K (ed.). Philosophical and Historical Roots of Occupational Therapy. New York: Haworth Press.

Dwairy M (1998). Mental health in Arab society. In: Bellack AS, Hersen M (eds). Comprehensive Clinical Psychology. 10(13): 313-324. Oxford: Pergamon.

Dwairy M, Van Sickle TD (1996). Western Psychotherapy in Traditional Arabic Societies. Clinical Psychology Review 16(3): 231-249.

Eccleshall R (2003). Liberalism. In: Eccleshall R, Finlayson A, Geoghegan V, Kenny M, Lloyd M, Mackenzie I, Wilford R (eds). Political Ideologies: An Introduction. London: Routledge.

Fitzgerald MH (2004). A dialogue on occupational therapy, culture, and families. American Journal of Occupational Therapy 58(5): 489-498.

Fitzgerald MH, Mullavey-O’ Byrne C, Clemson L (2001). Families and nursing home placements: a crosscultural study. Journal of Cross-Cultural Gerontology 16: 333-351.

Ghuloum S, Ibrahim MA (2006). Psychiatry in Qatar International Psychiatry 3(4): 16-18.

Greene R (2009). OT in Oman. (Available at: http://www. wfot.org.au) (Accessed 4 September 2009).

Hammad A, Kysia R, Rabah R, Hassoun R, Connelly M (1999). ACCESS guide to Arab culture: health care delivery to the Arab American community. Community Health \& Research Center, Public Health Education and Research Department, Series of Research Report No (7).

Hasselkus BR (2002). The Meaning of Everyday Occupation. Thorofare USA: SLACK Incorporated.

Hopton K, Stoneley H (2006). Cultural awareness in occupational therapy: the Chinese example. British Journal of Occupational Therapy 69(8): 386-389.

Hsiao FH, Klimidis S, Minas H, Tan ES (2006). Cultural attribution of mental health suffering in Chinese societies: the views of Chinese patients with mental illness and their caregivers. Journal of Clinical Nursing 15: 998-1006.
Hume C (2002). Why a global perspective can benefit occupational therapy. British Journal of Occupational Therapy 9(6): 205.

Hurreiz SHA (2002). Folklore and Folklife in the United Arab Emirates. London: Routledge Curzon.

Ismail H, Wright J, Rhodes P, Small N (2005). Religious beliefs about causes and treatment of epilepsy. British Journal of General Practice 55: 26-31.

Iwama MK (2003). Toward culturally relevant epistemologies in occupational therapy. The American Journal of Occupational Therapy 57(5): 582-588.

Iwama MK (2007). Culture and occupational therapy: meeting the challenge of relevance in a global world. Occupational Therapy International 14(4): 183-187.

Jabbour S (2003). Health and development in the Arab world: which way forward? BMJ 326: 1141-1143.

Kelly L (1995). What occupational therapists can learn from traditional healers. British Journal of Occupational Therapy 58(3): 111-114.

Kielhofner G (2002). The environment and occupation. In: Kielhofner G (ed.). Model of Human Occupation: Theory and Application (3rd Edition, pp. 99-113). Maryland, USA: Lippincott Williams and Wilkins.

Kirsh B, Trentham B, Cole S (2006). Diversity in occupational therapy: experiences of consumers who identify themselves as minority group members. Australian Occupational Therapy Journal 53: 302-313.

Lamport NK, Coffey MS, Hersch GI (2001). Activity Analysis \& Application (4th Edition, pp. 5-10). Thorofare: Slack.

Lim KH (2008). Working in a transcultural context. In: Creek J, Lougher L (eds). Occupational Therapy and Mental Health (4th edition, pp. 251-274). Edinburgh: Elsevier.

Loveland C (1999). The concept of culture. Cross-cultural Rehabilitation: An International Perspective (pp. 15-24). London: Sanders.

Malin N, Wilmot S, Manthorpe J (2002). Key Concepts and Debates in Health and Social Policy. Maidenhead: Open University Press.

Malinak C (2007). Doing business in Oman: Oman social and business culture. CIA World Factbook. London: Communicaid Group Ltd.

Miles M (1995). Disability in an eastern religious context: historical perspectives. Disability and Society 10(1): 49-69.

Nelson A (2007). Seeing white: a critical exploration of occupational therapy with Indigenous Australian people. Occupational Therapy International 14(4): 237-255.

Nettleton S (1997). Governing the risky self: how to become healthy wealthy and wise. In: Peterson A, Bunton R (eds). Foucault, Health and Medicine. London: Routledge. 
Razali SM, Aminah K, Khan UA (2002). Religious-cultural psychotherapy in the management of anxiety patients. Trancultural Psychiatry 39(1): 130-136.

Reed KL, Sanderson SN (1999). Concepts of Occupational Therapy (4th edition, pp. 3-44). USA: Lippincott Williams \& Wilkins.

Saks M (1995). Professions and the Public Interest: Medical Power, Altruism and Alternative Medicine. London: Routledge.

Taylor HB, Hudson D (2005). Cultural differences: the experience of establishing an occupational therapy services in a developing community. Australian Occupational Therapy Journal 52: 188-198.
Yamey G, Greenwood R (2004). Religious views of the 'medical' rehabilitation model: a pilot qualitative study. Disability and Rehabilitation 26(8): 455-462.

Yang S, Shek MP, Tsunaka M, Lim HB (2006). Cultural Influence on occupational therapy practice in Singapore: a pilot study. Occupational Therapy International 13(3): 176-192.

Yau MK (2003). Cultural competence in OT practice. Occupational Therapy International 11(1): 29.

Ypinazar VA, Margolis SA (2006). Delivering culturally sensitive care: the perception of older Arabian Gulf Arabs concerning religion, health, and disease. Qualitative Health Research 16(6): 773-787. 